\title{
Los pueblos originarios y la democracia en Argentina: avances y desafíos
}

\author{
Macarena Del Pilar Manzanelli \\ Doctoranda en Antropología Social (Universidad Nacional de San Martín, Argentina) \\ San Martin, Argentina \\ mdpmanzanelli@gmail.com
}

\begin{abstract}
Resumen
El presente trabajo reflexiona acerca de los avances, obstáculos y desafios del modelo de Estado, de la democracia y de la democratización argentinas en relación al proceso de visibilidad-invisibilidad de los pueblos originarios entre los años 1990 y 2014. Indaga acerca de las continuidades/discontinuidades entre un orden democrático de carácter neoliberal y otro nacional-popular respecto a la cuestión indígena. Específicamente, busca dejar expuestas ciertas inquietudes respecto a la relación entre el Estado y los pueblos originarios en dicho período, a profundizar en futuros investigaciones. Para ello, a partir de la bibliografía acerca de los dispositivos jurídicos establecidos desde la sanción de la Ley Integral Indígena en 1985 y de los estudios culturales, el foco del trabajo se ubica en la aparición en 2009 y la intervención en la arena pública del Encuentro Nacional de Organizaciones Territoriales de Pueblos Originarios (ENOTPO). Desde allí se pretende avanzar en (re) pensar cuestiones como la democracia y la democratización.
\end{abstract}

Palabras clave: democracia; democratización; Estado; pueblos originarios; ENOTPO.

\section{Introducción}

$\mathrm{D}$ ESDE LA DÉCADA DE 1970 en adelante, nociones como las de multiculturalismo, diversidad cultural e interculturalidad han despertado interés tanto en la academia como en las agendas de los gobiernos en América Latina y de los organismos internacionales, incluso con cambios en las constituciones, leyes y políticas destinadas a diversas minorías de distintos países. Dicho interés se encuentra acompañado por diversas reivindicaciones de comunidades indígenas a lo largo de la región, que han llevado a replantear el tipo de relación entre estos grupos y el Estado. Argentina no se encuentra exenta a este escenario. En los últimos años diversas movilizaciones y organizaciones indígenas surgieron con el mensaje de reivindicar su identidad y por la incorporación y el reconocimiento formal y práctico de ciertos derechos.

Asimismo y desde las "salidas" democráticas en América Latina, los debates en torno a democratización, consolidación, calidad y transparencia democráticas también han ganado protagonismo. Ya sea como temáticas centrales en diversos congresos académicos o como, desde el área de la administración pública, en la búsqueda de nuevos consensos sociales, lógicas y procesos de descentralización y desconcentración de competencias y funciones desde la instancia nacional a la provincial o local y de participación ciudadana. En el marco de estas transformaciones y discusiones la noción de ciudadanía también ha sido replanteada. 
Este trabajo se propone: articular los tópicos diversidad cultural-multiculturalidad, específicamente en relación a pueblos originarios, y democracia-democratización, para reflexionar acerca de las características, avances y obstáculos de los modelos de Estado-nación, régimen democrático y ciudadanía; repensar la relación entre Estado y pueblos originarios, sin dejar de lado las transformaciones que ha tenido la matriz del mismo en las últimas cuatro décadas, cuando ha pasado de un "Estado mínimo" a uno considerado como postneoliberal; y reflexionar sobre los alcances de la democratización a partir de los procesos de agenciamiento de grupos indígenas y de "minorías" en general. Para ello, desde un enfoque de los estudios culturales considerando ideas como las de proyecto hegemónico y acciones de los llamados grupos (sub)alternos, las preguntas-eje son: ¿cómo se ha planteado la relación entre los pueblos originarios y el Estado argentino entre la década de 1990 y comienzos del nuevo siglo?; ¿hubo continuidades-discontinuidades entre un período y el otro?; en la caracterización de los patrones y lógicas de tratamiento y gestión de la diversidad cultural, ¿qué ideas nos pueden ser ofrecidas acerca del modelo de democracia y su calidad, avances y desafios?

En primer lugar, se planteará al proyecto del Estado-nación y al régimen democrático argentinos como de carácter hegemónico, retomando ideas de ciudadanía y de visibilidad e invisibilidad, marcación y demarcación de los grupos llamados (sub)alternos, en función de dilucidar la mirada teórica desde la cual se parte para entender la relación entre Estado y pueblos originarios. Luego se expondrán modalidades estatales de las últimas décadas respecto a la gestión de la diversidad cultural, específicamente atendiendo al caso de los pueblos originarios con el fin de problematizar esta relación. Se avanzará con el caso del Encuentro Nacional de Organizaciones Territoriales de Pueblos Originarios (ENOTPO), a quien la autora y su grupo de investigación ${ }^{1}$ acompañan desde 2012, para reflexionar en torno a estas relaciones. Finalmente, se dará lugar a las conclusiones.

\section{Proyecto nacional, democracia y procesos hegemónicos: revisión y características}

Una de las formas de análisis de la relación entre los pueblos originarios y el Estado argentino remite a efectuar una relectura de los proyectos nacionales estatales y sus características. Se los entiende como una configuración cultural particular en tanto conforma un marco y espacio de posibles prácticas, representaciones y formas de interrelación y articulación entre las partes que incluyen heterogeneidades, conflictividades y relaciones asimétricas de poder (Grimson, 2011). Como proceso social se encuentra organizado por un sector cuyas prácticas embebidas en valores y significados son dominantes. No obstante, no clausura la disputabilidad y la constante redefinición de dichos límites y marcos políticos y socioculturales ni la agencia de los sectores considerados (sub)alternos (Hall, 1984; Roseberry, 1994; Williams, 1980).

El Estado nacional argentino ha conservado desde su constitución la potestad de regular los procesos de visibilidad y de enunciación de los que son distintos al "nosotros cívico" que ha pretendido idealizar e interiorizar $^{2}$ (Yashar, 2005). Asimismo, ha establecido qué es público y qué cuestiones quedan relegadas o excluidas al ámbito de lo privado, lo natural, metafísico, estético o acultural (Williams, 1980). La élite unitaria y liberal como sector dominante se ha identificado con una matriz cultural de blanquitud (Briones, 2005), asociada a la pretensión de una homogeneización cultural de tipo europea-occidental y ha constituido una noción de ciudadanía de este tipo (Manzanelli, 2012), desmarcándose y marcando poblaciones que se alejaban de ese "ser nacional" pretendido (Segato, 2007). Dicha idea de ciudadanía se corresponde con una identidad nacional a partir de la negatividad de dos partes y de una lógica moderna de la diferencia (Grossberg, 2003): "un ser nacional homogéneo, blanco y al estilo europeo" y formaciones alternas, "otros".

Sintéticamente han coexistido tres lógicas estatales que caracterizan el tratamiento frente a los pueblos originarios a lo largo de los siglos: una de progreso por el puerto y expulsión-exterminio de los "estorbos" incivilizados, seguida de otra de argentinización y extranjerización y otra de negación e interiorización de las líneas de color (Briones, 2005). En este sentido, Carrasco (2000) menciona tres tipos de imágenes que se han creado en torno al indígena que se entremezclan y aún conviven en el imaginario social: la de indio estatua, cercano a la animalidad, como un primitivo testimonio o reliquia del pasado; la de salvaje indómito y nómada, culturalmente inferior que requiere de los mandatos civilizatorios; y la de ausencia indígena, en que el llamado "crisol de razas" triunfó y borró toda huella de diferencias. 
Este proceso de visibilidad-invisibilidad ha sido operacionalizado por medio de diversas tecnologías de poder (Grosso, 2007), o en términos de Grossberg (2003), mediante maquinarias estratificadoras, diferenciadoras y territorializadoras, que han establecido distintas identificaciones y pertenencias - lugares y no lugares - que determinan la agencia de los sujetos. Así, diversas estrategias han operado, tanto materiales como simbólicas. En cuanto a las primeras, se presentan la obtención de los recursos naturales y del territorio por medio de la ausencia de acciones legales ante usurpaciones por parte de los terratenientes, robos, establecimiento de métodos de arrendamiento, entre otros. Respecto a las segundas, se encuentran la formación de una identidad nacional homogénea y políticas identitarias, corporizadas de forma hegemónica en la noción de ciudadanía liberal. En la práctica se ha establecido un régimen democrático desigual de acceso a recursos simbólicos y materiales, ya sea en términos de derechos políticos, sociales y socio-culturales o en el acceso a tierras/territorios y recursos naturales, como se ve en la mayoría de las luchas indígenas.

Ahora bien, ¿qué vinculación presentan estas argumentaciones sobre los Estados nación como procesos hegemónicos con los tipos de democracia, los procesos de democratización y los tratamientos estatales de la diversidad cultural? El eje conductor que hilvana estos conceptos se centra en problematizar las características de los límites y las lógicas que hacen inteligible la interrelación y los posicionamientos otorgados a los diferentes actores-parte en estos proyectos de nación como marcos de constitución de alteridades (Briones, 2005; Segato, 2007). Así, un abordaje posible de este tópico enfatiza una perspectiva simbólica-hermenéutica antes que institucionalista-administrativa. Es decir, en cómo se ejerce el poder en función de los límites informales y formales traducidos en las constituciones y leyes, antes que efectuar una tipología de democracia, como ha acontecido desde la caída del Muro de Berlín y las "salidas democráticas" en América Latina”. También permite, siguiendo a Cheresky (2011), repensar en los tipos de "ciudadanía", que condensan una polifonía de experiencias públicas de distintos $-\mathrm{y}$ nuevosindividuos y colectivos que reclaman por derechos y su efectivización y que constituyen vínculos asociativos e identificaciones cambiantes. Uno de ellos, y desde dónde se presenta este trabajo, es el caso de los pueblos originarios. El tipo de democracia entonces cristaliza o actúa como espejo de las relaciones sociopolíticas, económicas y culturales.

Strasser (2000) y Subirats (2013) enfatizan en la paradoja que caracteriza al mundo político contemporáneo que la desigualdad se ha mantenido en constante crecimiento a pesar de procesos de mayor apertura democrática, inclusión de nuevos sectores a la vida pública y de nuevas plataformas vía las nuevas tecnologías de información y comunicación. No obstante, y en función del resurgimiento del reconocimiento de las diversidades culturales, sería oportuno reflexionar en torno a cómo la democracia en tanto régimen de verdad (Gil Araújo, 2006) puede responder a dichas demandas. Las mismas implican no sólo la obtención de derechos formales sino de legitimaciones de nuevas formas de subjetividades políticas e incluyen nuevas lógicas y discusiones como la racialidad-etnicidad y la cultura (Hall, 2010). Entonces, ¿qué ocurre cuando la desigualdad se juega en términos culturales y/o étnicos y en relación a la distribución del ingreso?; ¿o mismo cuando la democracia en tanto régimen estatal con sus instituciones occidentales definidas se encuentra con otras formas e instituciones que incluso se declaran preexistentes a la propia conformación del Estado?; ¿o cuando se encuentra ante la necesidad de redefinir su prototipo de ciudadano, que históricamente ha sido individualista, occidental y liberal?

\section{Lógicas de las democracias: la herencia moderna}

La democracia desde la "tercer ola" ha sido definida y defendida como el régimen por excelencia universal (Strasser, 2000; Cherescky, 2011; Ranciére, 2010). No obstante, en tanto régimen político de gobierno del Estado-nacional y liberal-capitalista no se la puede analizar escindiéndola del horizonte y orden social-político occidental-moderno que caracteriza dicha universalidad (Strasser, 2000). Para un análisis crítico, es necesario contextualizarla desde ciertas geografias de la imaginación y de la administración política (Trouillot, 2011). En este sentido, la relación entre Estado y sociedad civil se localiza desde una realidad y un relato-lenguaje que aun siendo particulares han devenido en universal y se han naturalizado como la única verdad posible y legítima de contar.

Características generales que presentan estas democracias reales y modernas como factores fundantes -y actualmente cuestionados - son la representatividad y la legitimidad que la sociedad confiere al orden político-institucional (Strasser, 2000). Subirats (2013), siguiendo a Rosanvellon (2006, citado en Subirats, 2013), identifica como creencias y supuestos de las democracias actuales la disposición de las mayorías como expresión automática de voluntad general que se legitima en el acto electoral. Desde la crítica a la identidad

3 Es necesario indicar que hay una vasta literatura desde la Ciencia Política al momento de definir tipologías de democracia ante su constante expansión y transfiguración (Cheresky, 2011). No obstante es necesario no caer en categorías abstractas que no permitan dilucidar relaciones sociales concretas (Isla, 2009). 
moderna de Grossberg (2003), surgen elementos centrales como relaciones en base a la diferencia entre un "nosotros-ellos", la individualidad, un sistema político que se fundamenta en la idea del individuo moderno con base en una organización social de propiedad privada $^{4}$ y una temporalidad específica de tipo evolucionista. En este sentido, Mattiace, Hernández, y Rus (2002) indican en su análisis de las transformaciones en México tras la derrota del PRI en 2000 y de su sistema corporativista que amplios sectores de la población en Chiapas, entre ellos indígenas, no se sentían reconocidos con el sistema democrático representativo cuya lógica se sustenta en el voto individual. Así, constituyeron experiencias de democracia comunitaria con base en su autodeterminación como alternativa al modelo de democracia clásica. En términos de O’Donnell (1994), la democracia como institución política refiere a territorios delimitados - ya sea en niveles nacionales, supra o subnacionales-, canales de acceso a la toma de decisiones y representación de identidades e intereses con influencia en los comportamientos y las expectativas de las personas. La democracia se presenta entonces como un tipo de régimen del Estado-nación que habilita subjetividades políticas y ejerce un control biopolítico a través de sus reglas formales e informales de participación.

Otra forma de definirla es para Strasser (2000) como un régimen mixto y sui generis. Él utiliza esta idea de mix para indicar que participan diversos grupos de interés con formas políticas específicas, como corporaciones, partidos, tecnócratas-burócratas y oligarcas. Rescato esta imagen de una democracia compuesta por un entretejido ambiguo de actores con sus propias lógicas, que acompañada de los cambios operados en los Estados-nación, conlleva a una mayor o menor participación y legitimación de grupos de la sociedad civil. Un espacio en donde sujetos individuales u organizados convergen en la escena público-política y buscan ser representados o autorepresentarse desde la movilización y organización autogestionada ante la crisis de canales institucionales.

Sintéticamente, nos encontramos ante un tipo de organización de la vida social-política que reconoce, administra y autoriza a las personas en función de un acuerdo en que una parte visible - la llamada mayoríanegocia las formas de representación posibles, derechos y obligaciones aceptables en tanto miembros de un tipo de ciudadanía democrática. Así, aun cuando la democracia como régimen de gobierno mantenga su lógica de la representatividad otorgada por un pueblo soberano mayoritario, un análisis policial ranceriano invita a pensar que los lugares enunciativos y materiales de los diversos actores y grupos no se encuentran equitativamente distribuidos ni reconocidos. $\mathrm{O}$ en términos de Santos (2012) es necesario reflexionar acerca de que en este tipo de democracia subyace un consenso de pluralismo político eurocéntrico de raíz liberal y con vestigios de colonialismo cultural, en que la interculturalidad ni la justicia indígena se expresan.

A continuación se puntualizará en los tratamientos indigenistas que reflejan la caracterización del proyecto hegemónico del Estado-nación y del régimen democrático para dar lugar a reflexiones acerca de nuevas formas de pensar a la democracia.

\section{Gestión de la diversidad cultural y la cuestión indígena en Argentina y los procesos de visibilidad-invisibilidad de los pueblos originarios}

Como indican Briones (2008) y García Canclini (2004), es prudente revisar cómo se ha interpretado y gestionado la diversidad cultural. De allí deriva su oportunidad o clausura para cuestionar estos proyectos nacionales y, junto a ellos, la idea de democracia representativa-liberal y su concepción de ciudadanía y para poder reconfigurar las modalidades del tipo de relación entablada por el Estado con los "otros", en este caso los pueblos originarios.

En Argentina desde fines de la década de 1980 y en sintonía con los diversos movimientos indígenas que han emergido a lo largo de Latinoamérica para reivindicar su identidad, se incorporaron y reconocieron formalmente ciertos derechos y a los mismos indígenas como sujetos de derecho por medio de la reforma constitucional, sanción de leyes y ratificación de tratados internacionales como lo es el Convenio 169 de la Organización Internacional del Trabajo (OIT) (Carrasco, 2000; Escobar, 2007; GELIND, 1999; Gordillo y Hirsch, 2010; Isla, 2009; Iturralde Guerrero, 1997; Lázzari, 2003; Schwittay, 2003). En este sentido, el prolifero cuerpo legislativo tanto a nivel nacional como internacional (Briones, en prensa; Enderé y Ayala, 2012) sirve como piso y antecedente jurídico para nuevos impulsos de reformas y cambios. Entre los principales antecedentes se encuentran: la Ley 23.302, que crea el Instituto Nacional de Asuntos Indígenas (INAI), sancionada en 1985 y reglamentada en 1989; la adopción del Convenio 169 de la OIT por la Ley 24.071 en 1992 y posterior ratificación en 2001, que establece el criterio 
de autodeterminación, el respeto a sus prácticas culturales y la responsabilidad de los gobiernos en desarrollar junto a los pueblos una acción coordinada y sistemática con miras a proteger los derechos; la reforma de la Constitución en 1994 con la inclusión del Art.75, inc. 17 , que reconoce la preexistencia de los pueblos originarios, sus autoridades y formas de organización social y cultural, la propiedad comunitaria de las tierras y la obligatoriedad de consulta y participación en los asuntos que los afecte; la Ley 24.544, de 1995, que aprobó la constitución del Fondo para el Desarrollo de los Pueblos Indígenas de América Latina y el Caribe; la Ley 24.874, de 1997, que adopta el Decenio Internacional de las Poblaciones Indígenas del Mundo; el Segundo Decenio Internacional de los Pueblos Indígenas del Mundo (resolución de la ONU, 2005); la Ley 26.160, de 2006, de posesión, propiedad y personaría jurídica de las tierras que ocupan tradicionalmente, evitando los desalojos; y la Declaración de las Naciones Unidas sobre Asuntos Indígenas, de 2007, guía interpretativa y vinculante para la Constitución Nacional que prevé el derecho de cada pueblo a conservar su institucionalidad propia, participar en la adopción de decisiones en las cuestiones que afecten a sus derechos por medio de representantes elegidos por ellos de conformidad con sus propios procedimientos y la cooperación de buena fe por parte de los Estados antes de adoptar y aplicar medidas legislativas y administrativas que los afecten, a fin de obtener su consentimiento libre, previo e informado. No obstante, los avances recientes son notorios pero no completos ni satisfactorios.

La interculturalidad ha tomado dos tipos de representaciones o umbrales, uno de la integración y otro de tolerancia (Briones, 2008). En cuanto al primero, se busca adaptar y asimilar a los "otros" a la producción simbólica, en este caso a una identidad nacional, al "ser nacional" o al "nosotros cívico". Se expresa una mera exposición de las diferencias como si fueran un mosaico de culturas distintas sin atender a sus causas históricas ni a las construcciones históricas que se han dado alrededor de las mismas, con el fin de una integración o de "reparación histórica". Los pueblos originarios son considerados como "ciudadanos incompletos" a los cuales el Estado debe tutelar y ofrecer garantías para su desarrollo. En cuanto al segundo, se le otorga un valor potencial a la diversidad cultural, como capital social, para el desarrollo cultural y socioeconómico de dichas poblaciones. No obstante, aparecen sesgos de índole económicos-neoliberales en que al reconocimiento de derechos culturales se une una retracción de derechos socio-económicos. En ambos casos, ya sea remarcando una línea de integración o de tolerancia, no se considera a la diversidad cultural o la interculturalidad como una construcción histórica (Briones, 2005) desde la cual los actores puedan negociar, interaccionar y confrontar en torno a estos espacios de diferencias y fronteras.

Dichas lógicas de relación entre el Estado y los pueblos indígenas se encuentran relacionadas con los modelos de Estado y democracia que también han variado en sus legitimaciones y formulaciones. Desde los años 1970, y especialmente en los 1990, éstos se han caracterizado en Argentina por ser de corte neoliberal con reconfiguraciones en el tipo de relación con la sociedad civil, por la pérdida de protagonismo de la política ante el predominio de una racionalidad de mercado y por el avance de una nueva ola de la globalización en que nuevos actores, como empresas transnacionales, ONGs y nuevas dimensiones, como lo global y lo local, toman fuerza. Asimismo, surgen nuevas formas de participación en que se pretende un ejercicio activo por parte de la ciudadanía dirigiendo la responsabilidad hacia la población interpelada (Lenton y Lorenzetti, 2005). Esta delegación de responsabilidades en la sociedad civil se relaciona con modelos de democracia participativa, en que adquieren centralidad las acciones de los grupos de la sociedad civil y la accountability vertical. O como indica Cheresky (2011), surgen democracias continuas en que los ciudadanos toman protagonismo más allá del momento electoral, emergiendo con frecuencia de la vida pública con sus reclamos y demandas, incluso son considerados como voces legítimas al momento de formular políticas públicas.

A partir de comienzos del siglo XXI, con la presencia de gobiernos de corte de izquierda o nacional-popular en Argentina, se ha propuesto una salida del Estado mínimo retomando el rol principal de desarrollo socioeconómico y de bienestar social excediendo las funciones básicas respecto a los servicios públicos. Este proyecto estatal-nacional encarado desde entonces puede ser entendido como una redefinición de hegemonía, autorizando y desautorizando prácticas e identificando opuestos como los sectores ubicados a la derecha del espectro político y considerados "oligarcas" (Retomazo, 2011), lo cual brinda una coyuntura histórica distinta a la presentada en las décadas de los 1980 y 1990. Específicamente desde la multitudinaria marcha de diversas organizaciones de pueblos originarios en el Bicentenario en $2010^{5}$, se ha reactivado la asociación indigenismo-inclusión social. La pertenencia ciudadana comenzó a interpretarse y problematizarse en términos de diferencias culturales y no sólo de clases (Briones, en prensa). Asimismo, la autora entiende que la adhesión al "proyecto nacional y popular" de ciertas organizaciones indígenas ${ }^{6}$ se amplía a otras cuestiones de índole

5 En 2010 se realizó una marcha multitudinaria de poblaciones indígenas en que han participado diversas organizaciones indígenas que acercaron a la presidenta argentina, Cristina Fernández de Kirchner, diversos documentos en que presentaban sus principales reclamos. 6 Como es el caso del ENOTPO. 
de soberanía nacional-latinoamericana, no sin generar tensiones con sus diversas demandas. Por un lado, se presentan situaciones en que sus reivindicaciones confrontan con el patrón productivo extractivista y de generación de ingresos estatales. Y por otro, se acercan a partir de la identificación de adversarios políticos en común como se da en el caso de los terratenientes ligados a la denominada oligarquía rural. Santos (2012) reflexiona críticamente acerca de que los pueblos indígenas y sus formas de movilización política se encuentran entre rechazar absolutamente el tipo de gestión de la diversidad cultural que habilitan los Estados-nación o aceptarlo como una estrategia que les permita un grado de inclusión política para avanzar en la transformación del modelo político, es decir, hacia un modelo de Estado y de democracia con base en el respeto real a la multiculturalidad ${ }^{7}$ para avanzar con cambios como los constitucionales promulgados por gobiernos de corte de izquierda ${ }^{8}$. No obstante, como se ha indicado, ello no quita que el pluralismo eurocéntrico continúe dominando con prácticas que atentan contra modelos de inclusión social desde una lógica intercultural.

En cuanto al modelo democrático hay la coexistencia de un régimen participativo en que la vida ciudadana se extrapola de los canales institucionales y asume nuevas figuras y liderazgos, muchos de ellos populares. Para dar cuenta de la participación de los pueblos originarios, se han creado nuevas instituciones. En 2004 se constituyeron los Consejos de Participación Indígena (CPI) en diversas provincias argentinas como representantes de los pueblos indígenas; y en 2006 se crearon la Dirección de Pueblos Originarios, dependiente de la Secretaría de Ambiente y Desarrollo Sustentable, y la Dirección de Derecho de Afirmación Indígena. En este sentido, y como se verá, el Estado aún no escapando de las lógicas mencionadas comenzó a buscar acercamientos y generar vínculos directos con los mismos pueblos originarios, reconociendo su condición de sujetos políticos y de derechos, y no ya exclusivamente por medio de organizaciones no gubernamentales o civiles.

Dichos antecedentes también han permitido pensar y llevar adelante incluso la reforma y unificación del Código Civil de Vélez Sarsfield, de 1871, constituyendo una nueva forma de relación entre el Estado y la sociedad civil, de ordenamiento y de clasificación por parte de éste hacia los ciudadanos, en este caso específicamente hacia los pueblos originarios. Se han realizado diversas audiencias públicas entre agosto y noviembre del año 2012 en el Senado en pos de dar participación a las diversas voces y reflejar y visibilizar así el respeto a la diversidad cultural. El principal reto ha girado en torno a los debates por la inclusión de la propiedad comunitaria indígena como parte del Derecho Indígena en el nuevo código. A lo largo de los posicionamientos de las partes, tanto estatales como de miembros de diversos pueblos indígenas, se pudo dar cuenta de distintas formas de concebir a la tierra y al territorio y con ello de distintas lógicas subyacentes.

Nuevamente es allí, en las distintas formas de pensarse y proyectarse en tanto "nosotros" y "ellos", en que se evidencian y resurgen las distintas formas - y límitesde ser un ciudadano argentino completo y de una considerada minoría que busca reconocimiento especial e igualitario. En este caso reaparecieron vestigios de un tratamiento estatal de la diversidad cultural de carácter integracionista. Los reclamos de los pueblos indígenas y organizaciones territoriales y políticas propias como civiles acompañantes se centraron en: el no respeto a la consulta libre, previa e informada en cuanto a las propuestas de artículos que los regularía; la no inclusión del tipo de relación espiritual, cosmológica y cultural que mantienen con el territorio y que hace que no se trate de un inmueble rural, sino de una totalidad que abarca desde los recursos naturales hasta lugares sagrados y vínculos que se entablan; la necesidad de pensar e incluir la situación urbana de muchos pueblos producto de políticas de desarraigo y exterminio de las familias originarias desde tiempos de la conquista española, de forma tal que no sean entendidos como campesinos únicamente; el no respeto a la preexistencia que deriva del no reconocimiento de sus instituciones políticas propias y del pueblo como sujeto político y de derechos. Ello se vincula con el reclamo a la que la personería jurídica sea de derecho público no estatal y no se encuentre bajo derecho privado en asimilación a cualquier sociedad que el Estado instituye. En palabras de Alvarado (2015), ante estas justificaciones y aún ante las dudas que surgen acerca de si la inclusión de la Propiedad Comunitaria Indígena en el nuevo Código Civil era satisfactoria o no, la forma de operar del Estado nación argentino fue ilegal e ilegítima.

Entiendo que en el caso argentino ambas lógicas, de tolerancia e integración, sustentan el tratamiento de la diversidad cultural y se entremezclan en las diversas prácticas llevadas adelante por el Estado argentino

7 La multiculturalidad es entendida como una forma distinta al Ilamado multiculturalismo oficial (Taylor, 1997; Wade, 2008) en cuanto persigue una compresión socio-histórica de las diferencias y diversidades culturales en que aparecen diversas dimensiones y matices culturales, políticas, de poder y económicas (Briones, 2006; Mattiace, Hernández y Rus, 2002).

8 El autor resalta la constitución de Bolivia (2009), que en su artículo 11 reconoce tres formas de democracia: la democracia representativa, la democracia participativa y la democracia comunitaria, que correspondería al tipo de organización política de las comunidades indígenas. Afirma que la inclusión de esta tercera forma de democracia constituye uno de los retos principales de la plurinacionalidad en camino hacia una democracia intercultural. 
respecto a los pueblos originarios en la década de 1990 y comienzos del nuevo siglo 9 . Se presentan paradojas en las transformaciones del modelo de Estado y del tipo de relación con la sociedad civil de matriz neoliberal. Por un lado, ante nuevas formas de democracia como la participativa en que son los mismos ciudadanos quienes gestionan sus reivindicaciones, se habilitan instrumentos y canales políticos, incluso extra-institucionales, de inclusión de demandas en la agenda público-estatal y nuevas formas de control ciudadano que pueden ser alentadores para diferentes sectores de la población, entre ellos las "minorías" y su organización política. Ese legado continúa presenta en el tipo de modelo de cambio de siglo, que ante un giro que abre sus puertas a temas de inclusión social y de los sectores considerados (sub)alternos o populares, puede potenciar el protagonismo y dicha oportunidad para estos sectores. No obstante, y allí la contradicción inherente al modelo estatal-nacional occidental moderno y su sistema político, ello no quita que en estas nuevas herramientas y formas de participación política e integración, los mismos sectores populares logren desafiar y transformar los elementos que caracterizan a estas democracias reales y modernas y en sí al modelo cultural dominante distintivo del Estado-nación argentino.

Ahora bien, hasta el momento se ha presentado al régimen democrático desde las lógicas de gestión de la diversidad cultural y de la relación entre el Estado y los pueblos originarios bajo premisas y fundamentaciones político-filosóficas que si bien abren nuevos canales de participación, mantienen, como también señala Prada Alcoreza (2011) acerca de la formación del Estado Plurinacional de Bolivia, características etnocéntricas y estado-céntricas. Así, cabe preguntar ¿qué desafios - y esperanzas - quedan para los sectores (sub)alternos? Para ello, me centraré en reflexiones en torno al accionar en Argentina de una organización territorial-política de pueblos originarios, el ENOTPO, lo que permite repensar la caracterización de las democracias participativas y continuas y acercarnos hacia una mirada, en términos rancerianos, política de la democracia antes que policial.

\section{El caso del ENOTPO ${ }^{10}$}

El ENOTPO, que agrupa en torno de 45 organizaciones de 1.000 comunidades pertenecientes a 27 pueblos originarios distintos en Argentina, nació en 2009 como un proceso de articulación política de dichos pueblos frente al Estado, bajo la propuesta de construir un Estado Plurinacional e Intercultural, que respete y visibilice la diversidad cultural y sus identidades. Con la conformación de esta organización territorial-política profundizan la idea de ser portadores de una identidad propia y de un proceso de reconstrucción y fortalecimiento de la misma de forma tal de revertir el largo proceso de sometimiento, negación e invisibilidad y dejando de ser meros objetos de las políticas públicas para ser sujetos de derechos de forma efectiva. Así, se entiende que cuestionan, negocian y se (re)posicionan frente a los valores y prácticas hegemónicas impuestos por el Estado-nación, como el régimen de ciudadanía y de identidad hegemónica cívica presentada que han negado e invisibilizado a otras identidades y culturas como la de los pueblos originarios por medio de diversas tecnologías políticas.

Entre las acciones que se han identificado como parte de un nuevo camino de los pueblos indígenas del ENOTPO en esta nueva coyuntura histórica del proyecto estatal se pueden mencionar: la nueva Ley de Servicios de Comunicación Audiovisual, $n^{\circ}$ 26.522, sancionada en 2009, con su propuesta de inclusión del derecho a una comunicación con identidad, la cual ha sido impulsada en parte por este encuentro; la participación en las audiencias públicas de la nombrada "Reforma del Código Civil de aplicación ideal de Estado liberal, europeo y occidental", en alusión al Código Civil de Vélez Sarsfield, definido por ENOTPO como una "herramienta de opresión justificadora de un orden individualista, negador de la diversidad cultural y los derechos colectivos"; la presentación del Protocolo de Consulta Previa, Libre e Informada elaborado por ENOTPO con el pedido que sea vinculante, junto con el Convenio 169 de la OIT, entregado en 2013 a autoridades oficiales; la iniciativa de remover la estatua de Cristóbal Colón, ubicada detrás de la Casa Rosada, acto simbólico considerado como alteración en los símbolos y significaciones en torno a los cuales se ha constituido la identidad nacional europeizante; y la sanción de la Ley de Soberanía Alimentaria, en 2015, después de un trabajo conjunto con la Secretaría de Agricultura Familiar y el Ministerio de Agricultura, Ganadería y Pesca.

Si bien cada propuesta apunta a temáticas específicas, se puede dar cuenta de ciertos ejes generales desde los cuales ENOTPO se posiciona ante el Estado. Como cuerpo colectivo su mensaje gira en torno a identidad, territorio y memoria-preexistencia.

9 Así, por un lado Briones (2008) y GELIND (1999) encuentran un tipo de representación de carácter integracionista, por ejemplo en la Ley Federal de Educación o en la Ley 23.302, creadora del INAI, o como presentan Lenton y Lorenzetti (2005), desde el 2001, se está ante una modalidad neoindigenista.

10 Así como los proyectos hegemónicos son heterogéneos, también el sector llamado (sub)alterno presenta diversos matices, diferencias, tensiones y ambigüedades dentro de él. Por lo tanto, ENOTPO conforma una de las principales, pero hay otras organizaciones y posiciones políticas de los pueblos originarios en Argentina. 
La identidad indígena se expresa en forma genérica, pero adquiere formas particulares en las identificaciones que los diferentes pueblos del ENOTPO articulan de acuerdo a sus prácticas culturales, es decir, a costumbres, creencias, cosmologías, lengua y otros diacríticos en términos barthianos. Ello no implica que dichas prácticas sean consideradas de forma estática o incluso esencialista, sino que se generan interrelaciones de las mismas que pueden derivar en diferentes narraciones del yo individual y social. Ahora bien, el énfasis en las identidades indígenas nos remite al contraste con el tipo normativo de identidad nacional blanca y homogénea que ha tomado el Estado como proyecto nacional y que lo ha vehiculizado en diferentes estrategias y dispositivos materiales y simbólicos.

El territorio es encarado como una totalidad, un espacio indivisible que engloba los aspectos sociales, religiosos-espirituales y económicos e incluye elementos tanto materiales como inmateriales. En las propuestas es presentado con un valor integral y colectivo de la vida indígena a partir de los vínculos ancestrales con el mismo e incorpora a la naturaleza desde un rol activo y de agencia, con influencia en la reproducción de sus vidas, a su vez, en contraposición a la forma occidental y moderna de entender a la tierra como un inmueble de propiedad privada y bajo una lógica económico-comercial-extractivista.

La memoria se encuentra estrechamente relacionada a, por un lado, las luchas de sus descendientes, que presentan continuidades, sedimentaciones y legados, y se presenta como un campo en que sus sentidos y significaciones se disputan (Briones, 2007). De hecho, muchas historias particulares de indígenas han sido ocultadas por la historia oficial autorizada. En este sentido, se habla de un Estado que mantiene una deuda histórica con los indígenas a reparar. Por otro lado, la memoria se relaciona con la preexistencia a la propia formación del Estado-nación. Desde esta conexión con el pasado es que reclaman sus derechos al territorio, a diversos recursos naturales y a una organización jurisdiccional propia, entre otros reclamos que superan el reconocimiento formal desde las leyes, como en el caso del art. 75, inc. 17, de la Constitución Nacional.

$\mathrm{Su}$ agenda política gira en torno actualmente a la elaboración de una ley que reglamente la posesión y titularización de la propiedad comunitaria indígena ${ }^{11}$. La misma es significativa dado que trata de un tema de sensibilidad para los pueblos indígenas, ya sea por la particular relación que mantienen con los territorios como por los continuos avasallamientos y desalojos que viven en los las provincias aun estando vigente la prórroga de la Ley 26.160. Tanto esta ley como nuevas políticas y temas como la soberanía alimentaria encuentran su espíritu en el instrumento que les ha permitido obtener un reconocimiento significativo como sujeto político y de derecho: la aplicación del Protocolo de Consulta Libre, Previa e Informada. La consulta también da cuenta del respeto a la autoderminación de sus instituciones y formas colectivas y comunitarias de organización del territorio, del espacio y de la temporalidad. Articular con el Estado para el ENOTPO implica llegar a acuerdos interculturales en que se logre el respeto a las cosmologías de las cuales parten cada actor y avanzar en leyes que protejan sus perspectivas culturales.

¿Qué nos dicen estos ejes de reclamos y reivindicaciones del tipo de democracia y del proceso de democratización en Argentina? ¿De qué forma el orden democrático trata las voces heterogéneas y sus propuestas y las relaciona con el sistema jurídico-institucional y la agenda pública estatal? ¿Se puede pensar en un orden democrático que dé lugar a estos "otros alternos" sin avasallar sus integridades? ¿Un modelo de Estado democrático que incluya formas de autodeterminación, organización e instituciones no occidentales con distintas nociones de la espacialidad que incluso conllevarían a rediseñar las fronteras administrativas jurídicas internas y externas de los Estados-nación?

\section{Reflexiones finales}

Considero, en primer lugar, que la interlocución del ENOTPO con el Estado refleja por un lado la reproducción de las lógicas de la diferencia desde las cuales se ha constituido el modelo de Estado-nación y de democracia representativa. En este sentido, se observa la inclusión de polifonías que supone un orden democrático que marca distinciones, ya sea en función de otra producción de identidad o desde las fronteras que ha establecido el Estado a partir de su constitución. Dichas diferencias se pueden rastrear en que la preexistencia de los pueblos originarios señala una frontera-división espacial-temporal con el Estado; la identidad indígena contrasta con una identidad europeizante-nacional; el territorio-Madre Tierra no puede equipararse a los sentidos asociados a la tierra del orden moderno-occidental como inmueble.

No obstante, aun manteniéndose estas lógicas desde la cual tanto el ENOTPO como el Estado se enuncian y posicionan, el orden democrático no podría entenderse como un juego de suma cero. Su reformulación y cambios como se presenta en la caracterización de las democracias continuas también debería recuperar la pregunta - antes que la respuesta - por asumir nuevas lógicas distintas a las autorizadas hasta el momento. Si ante la crisis de los canales de representación se originan nuevas formas participativas que refuerzan las experiencias comunitarias con plataformas que les 
permitan conectarse e incidir en los procesos de tomas de decisiones y formulación de políticas públicas (Subirats, 2013), será necesario pensar en cómo dicha participación e inclusión de los actores ${ }^{12}$, especialmente en el caso de los sectores (sub)alternos, en la vida público-política puede dar lugar a giros transformadores que escapen a lógicas utilitaristas y etnocéntricas. Ello invita a pensar a la democracia como un régimen en que al tener movimientos inestables y ambiguos (Cheresky, 2011) puede abrir lugares para los distintos actores y sus voces, incluyendo la conflictividad y heterogeneidad.

En este sentido, la fundamentación del reconocimiento de derechos en base a lógicas de la diferencia debe ser entendida como una parte del proceso de construcción de heterogeneidades que no se reduce a ellas, aunque sí refiere al tratamiento histórico que ha tenido la cuestión indígena desde el Estado, entre un "nosotros-ellos". Lo que se afirma es pensando desde el planteo de Abu-Lughod (2005), Briones (2007) y Grimson (2011), entre otros autores, en cuanto es imprescindible contextualizar la diferencia para no reificarla, como desde el planteo de Hall (2010) en cuanto que las identidades no implican una correspondencia necesaria o determinada ${ }^{13}$. Por todo eso, la democracia y el proceso de democratización no deben reducirse a la inclusión de las llamadas minorías en términos estáticos de nacionalización, culturización o etnización de los accesos a derechos y de los recursos simbólicos-materiales.

Por su parte, la llegada de un gobierno de carácter nacional-popular no subsana las dificultades presentadas por el tipo de tratamiento de la diversidad cultural y por el reconocimiento de las diferencias bajo modalidades de integración y de tolerancia, dado que las leyes implementadas continúan teniendo como base dichas lógicas occidentales-modernas, que se encuentran estrechamente relacionados con un modelo de Estado y así de democracia en que subyace la regla de representación de una mayoría que desde un análisis simbólico-cultural universaliza y naturaliza a un tipo de subjetividad política particular: individualista, diferente y blanco-europeo-moderno. En este sentido el proyecto estatal-nacional hegemónico mantiene un legado en que sus premisas son etnocéntricas. Así, las democracias actuales aun cuando busquen en sus modelos incluir nuevos formatos de participación de grupos sociales, no logran superar dichos límites.

Una primera impresión daría cuenta de que nada cambió en la relación entre el Estado y los pueblos originarios en Argentina. Sin embargo, es necesario sí identificar dos discontinuidades. La primera se refiere a que ha surgido un nuevo tipo de legitimación del Estado con la recuperación de su rol social, en que al menos desde la agenda público formal los sectores (sub) alternos-populares pasan a tener visibilidad. Luego, y manteniendo la crítica acerca de cómo se incluyen y cómo se visibiliza a dichos grupos, se cuenta con la emergencia de actores políticos que se definen más allá de los canales institucionales-representativos clásicos, tomando la voz en primera persona y redimensionado la política.

El caso presentado fue del ENOTPO, que permite redefinir dicha relación, abriendo nuevos caminos y propuestas que lleven a pensar y a considerar el tratamiento de la diversidad cultural y de las diferencias desde otras perspectivas. Una puede ser la de (des) construcción, sin descontextualizar ni "fijar" la historia y lucha indígena y reconociendo realmente su poder de agencia. Incluso en los diversos proyectos que presenta, el ENOTPO cuestiona críticamente las lógicas del Estado-nación de regularlos como también los dispositivos legales y las lógicas desde la cuales el Estado-nación interpreta y clasifica temas como la propiedad comunitaria indígena en los debates dados en las audiencias públicas por la reforma del Código Civil. Aun cuando el contenido de sus demandas y reivindicaciones pueda ser caracterizado bajo identificaciones étnico-culturales, por ejemplo al entender que la propiedad comunitaria indígena pueda ser definida desde su carácter preexistente al Estado-nación y desde la relación particular cosmológica que mantienen con el territorio, ello no impide de incluir y problematizar las situaciones de urbanidad de muchos pueblos, lo cual implica sumar en la discusión dimensiones histórico-político-estructurales. De esta forma la política indígena propone un reconocimiento diferencial de carácter intercultural para lograr la efectiva igualdad que rezan las leyes y que propone el régimen democrático.

Este ejemplo parece ilustrativo para lo que se quiere dar cuenta, no obstante no agota la infinidad de prácticas que realiza el ENOTPO, ya sea mediante intervenciones jurídicas como por diversos actos cotidianos que son festivales, pronunciamientos, charlas, entre otros ${ }^{14}$. Estas formas de interacción por parte del encuentro pueden enmarcarse en nuevas formas de entender a la ciudadanía e incluso al orden democrático. Desde diversos autores (García Linera, S/F; Lucio, 2004) se ha planteado la redefinición del modelo de democracia representativa, y liberal, a uno de carácter

12 En este sentido, el autor señala que no alcanza con solamente debatir sobre democracias participativas si la discusión se reduce a una complementación de la democracia representativa institucional.

13 Lo dicho implica abrir la posibilidad de un análisis no reduccionista del necesario reconocimiento y certeza de que los grupos sociales tienen determinados contenidos culturales - aun considerándolos dinámicos - e invita a pensar que si bien ello es posible, hay un abanico de relaciones heterogéneas y matices de pensar las diferencias, mismo dentro de los sectores considerados (sub)alternos.

14 Para más detalles, ver <www.enotpo.com.ar>. 
participativo con nuevos canales de interacción con la población respetando su organización social-política y cultural. Si bien lo dicho no elimina que quien establece los modos de participación formales continúa siendo el Estado-nación, existen momentos de rupturas y de intervención que muestran la distancia entre un orden democrático ideal y el real. Allí radican los obstáculos y a su vez los desafios y las oportunidades a un proceso de democratización del acceso a derechos y su efectivización en que la inclusión y participación no se den de forma paternalista y no se entiendan bajo modalidades estandarizadas, dadas a priori, sino contingentes, como parte de construcciones sociohistóricas más amplias.

Un nuevo modelo de Estado, con un orden democrático que presente un pasaje de una ciudadanía representativa liberal a otra de carácter participativo y continuo- y no meramente en lo formal -sólo podrá superar estas limitaciones ofreciendo lugar a una real participación de espacios políticos dirigidos por los mismos afectados. En este sentido, la oportunidad se encuentra en el accionar y la organización de estos grupos que interpelen al Estado desde sus propias lógicas y haciendo efectivos estos "avances" formales. Así, la ciudadanía y el orden democrático podrán ser entendidos como opuestas a la idea de exclusión y no se reducirán a una mera inclusión que no respete los agenciamientos de los colectivos "minoritarios". Ello también redundará en una optimización de la calidad democrática, en que la calidad sea pensada desde estos cambios cualitativos.

Lo descrito a partir del caso de ENOTPO en Argentina aporta algunas reflexiones sobre los procesos de democratización en materia de heterogeneidades culturales:

- En tanto formas de ordenamiento y distribución sociales, políticos, económicos y culturales hegemónicos de los grupos sociales, pueden ser entendidos como sedimentaciones de lógicas que presentan continuidades y bifurcaciones o resignificaciones que dan lugar a aperturas o cierres de expresiones de nuevas subjetividades.

- Lógicas que se expresan en las interlocuciones contingentes y estratégicas de los actores, como Estado y ENOTPO, y se pueden traducir en términos de etnicidad y nacionalización. El riesgo se corre si se esencializa o fija al proceso de democratización en dichos términos no atendiendo a las heterogeneidades y a las formas en que se construyen y posicionan social y políticamente los actores, tanto el Estado-nación como los pueblos originarios.

- Son limitantes y sujeciones de los procesos de los colectivos "minoritarios"/(sub)alternos en cuanto establecen las "reglas del juego" de qué se puede decir y qué no. No obstante, ello no anula la capacidad de agencia y de performance de estos grupos, como se ha visto en el caso de ENOTPO.

- Encierran campos de lucha y tensión constitutivos acerca de los sentidos de pertenencia, identidades y relaciones público-privadas que se traducen en modelos de ciudadanía cuya eficacia simbólica se refleja en los accesos a derechos y recursos materiales.

\section{Referencias}

ABREUT DE BEGHER, Liliana. La propiedad comunitaria indígena. Lecciones y Ensayos, n. 90, p. 55-97, 2012.

ABU-LUGHOD, Lila. La interpretación de las culturas después de la televisión. Etnografías Contemporáneas, n. 1, p. 57-91, 2005.

ALVARADO, Paula. Regulación de la propiedad comunitaria indígena en el proyecto de unificación del Código Civil y Comercial de la Nación (2012-2013). En: KOSOVSKY, Fernando (comp.). Dossier propiedad comunitaria indígena. Comodoro Rivadavia: EDUPA, 2015.

BRIONES, Claudia. Formaciones de alteridad: contextos globales, procesos nacionales y provinciales. En: BRIONES, Claudia (comp.). Cartografías argentinas. Políticas indigenistas $y$ formaciones provinciales de alteridad. Buenos Aires: Editorial Antropofagia, 2005.

. Teorías performativas de la identidad y performatividad de las teorías. Tabula Rasa, n. 6, p. 55-83, 2007.

. Diversidad cultural e interculturalidad: ¿de qué estamos hablando?. En: GAR CÍA VÁZQUEZ, Cristina (comp.).
Hegemonía e interculturalidad. Poblaciones originarias y migrantes. La interculturalidad como uno de los desafíos del siglo XXI. Buenos Aires: Prometeo, 2008.

Políticas indigenistas en Argentina: superficies de emergencia de la hegemonía neoliberal y de la "nacional y popular". En prensa. CARRASCO, Marita. La población indígena en Argentina. En: CARRASCO, Marita (comp.). Los derechos de los pueblos indígenas en Argentina. Buenos Aires: IGWIA y Vinciguerra, 2000 .

CHERESKY, Isidoro. Ciudadanía y democracia continua. Temas y Debates, v. 15, n. 22, p. 19-49, 2011.

ENDERÉ, María Luz; AYALA, Patricia. Normativa legal, recaudos éticos y práctica arqueológica. Un estudio comparativo de Argentina y Chile. Revista de Antropología Chilena, v. 44, n. 1, p. 39-57, 2012.

ESCOBAR, Diego. Los dones étnicos de la nación. Identidades huarpe y modos de producción de soberanía en la Argentina. Buenos Aires: Prometeo, 2007.

GARCÍA CANCLINI, Néstor. La cultura extraviada en sus 
definiciones. En: GARCÍA CANCLINI, Néstor. Diferentes, desiguales y desconectados. Mapas de la interculturalidad. Barcelona: Gedisa, 2004.

GELIND (Grupo de Estudios de Legislación Indígena). Etnografía del discurso sobre lo indígena. Publicar en Antropología y Ciencias Sociales, v. 8, p. 51-68, 1999.

GARCÍA LINERA, Álvaro. Autonomías indígenas y Estado multicultural. Una lectura de la descentralización regional a partir de las identidades culturales, S/F. Disponible en $<$ http://www.bivica.org/upload/autonomias-indigenas-Estado.pdf>. Acceso en 15 Ago. 2015.

GIL ARAÚJO, Sandra. Las argucias de la integración. Construcción nacional y gobierno de lo social a través de las políticas de integración de inmigrantes Los casos de Cataluña y Madrid. Madrid, 2006. Tesis (Doctorado en Sociología) - Universidad Complutense de Madrid.

GORDILLO, Gastón; HIRSCH, Silvia (comps.) Movilizaciones indígenas e identidades en disputa. Buenos Aires: La Crujía Editores, 2010.

GRIMSON, Alejandro. Configuraciones culturales. En: GRIMSON, Alejandro. Los límites de la cultura. Crítica de las teorías de la identidad. Buenos Aires: Siglo XXI, 2011.

GROSSBERG, Lawrence. Identidad y estudios culturales: ¿no hay nada más que eso?. En: HALL, Stuart; DU GAY, Paul (comps.). Cuestiones de identidad cultural. Buenos Aires: Amorrortu, 2003.

GROSSO, José Luis. Indios muertos, negros invisibles. Hegemonía, identidad y añoranza. Córdoba: Encuentro Grupo Editor, 2007. HALL, Stuart. Notas sobre la deconstrucción de "lo popular”. En: SAMUEL, Ralph. (comp.). Historia popular y teoría socialista. Barcelona: Crítica, 1984.

. La cuestión multicultural. En: RESTREPO, Eduardo; WALSH, Catherine;VICH,Víctor (comps.). Sin garantías: trayectorias y problemáticas en estudios culturales. Popayán, Lima, Bogotá y Quito: Envión, Instituto de Estudios Peruanos, Pontificia Universidad Javeriana y Universidad Andina Simón Bolívar, 2010.

ISLA, Alejandro. Los usos políticos de la identidad. Criollos, indígenas y Estado. Buenos Aires: Libros de la Araucaria, 2009.

ITURRALDE GUERRERO, Diego A. Demandas indígenas y reforma legal: retos y paradojas. Alteridades, v. 7, n. 14, p. 81-98, 1997.

LÁZZARI, Axel. Aboriginal recognition, freedom, and phantoms: The vanishing of the ranquel and the return of the rankülche in La Pampa. Journal of Latin American Anthropology, v. 8, n. 3, p. 59-83, 2003.

LENTON, Diana; LORENZETTI, Mariana. Neoindigenismo de necesidad y urgencia: la inclusión de los pueblos indígenas en la agenda del Estado neoasistencialista. En: BRIONES, Claudia (comp.). Cartografías argentinas. Políticas indigenistas y formaciones provinciales de alteridad. Buenos Aires: Editorial Antropofagia, 2005.

LUCIO, Adriana T. de. Nuevos movimientos sociales y democracia participativa. En: ROMERO, Ricardo (comp.). Democracia participativa, una utopía en marcha. Reflexiones, experiencias y un análisis del caso porteño. Buenos Aires: Ediciones Cooperativas y GEDEP, 2004.
MANZANELLI, Macarena Del Pilar. Multiculturalismo: una revisión a los proyectos nacionales de los Estados en América Latina, la noción de democracia liberal y de una ciudadanía excluyente. In: XII Jornadas Nacionales de Ciencia y Filosofía Política, 2012, Mar del Plata.

MATTIACE, Shannan L.; HERNÁNDEZ, Rosalva Aída; RUS, Jan. Introducción. Encuentros múltiples. En: MATTIACE, Shannan L.; HERNÁNDEZ, Rosalva Aída; RUS, Jan (comps.). Tierra, libertad y autonomía: impactos regionales del zapatismo en Chiapas. Chiapas: Centro de Investigaciones y Estudios Superiores en Antropología Social y International Work Group for Indigenous, 2002.

O'DONNELL, Guillermo. Delegative democracy. Journal of Democracy, v. 5, n. 1, p. 55-69, 1994.

PRADA ALCOREZA, Raúl. Horizontes de la descolonización y del Estado plurinacional. Ensayo histórico y político sobre la relación de la crisis y el cambio. 2011. Disponible en <http:// rosalux-europa.info/userfiles/file/Prada_Horizontes_de_la_ descolonizacion_y_del_Estado_plurinacional.pdf $>$.

RANCIÉRE, Jacques. El desacuerdo. Política y filosofía. Buenos Aires: Nueva Visión, 2010.

RESPUELA, Sofia. La democracia: una discusión en torno a sus significados. En: PINTO, Julio (comp.). Introducción a la Ciencia Política. Nueva versión. Buenos Aires: Eudeba, 2007.

RETOMAZO, Martín. Movimientos sociales, política y hegemonía en Argentina. Polis, n. 28, 2011. Disponible en $<$ http://polis.revues.org/1249>.

ROSEBERRY, William. Hegemony and the language of contention. En: JOSEPH, Gilbert M.; NUGENT, Daniel (eds.) Everyday forms of State formation: revolution and the negotiation of rule in modern Mexico. Durham, NC: Duke University Press, 1994.

SANTOS, Boaventura de Sousa. Cuando los excluidos tienen derecho: justicia indígena, plurinacionalidad e interculturalidad. En: SANTOS, Boaventura de Sousa y RODRÍGUEZ, José Luis Exeni (comps.). Justicia indígena, plurinacionalidad e interculturalidad en Bolivia. La Paz: Fundación Rosa Luxemburgo y Abya-Yala, 2012.

SCHWITTAY, Anke. From rural workers to indigenous citizens: the articulation of an indigenous identity and land struggle in northwestern Argentina. Journal of Latin American Anthropology, v. 8, n. 3, p. 127-154, 2003.

SEGATO, Rita. Introducción e identidades políticas/alteridades históricas: una crítica a las certezas del pluralismo global. En: SEGATO, Rita. La nación y sus otros. Buenos Aires: Prometeo, 2007.

STRASSER, Carlos. Democracia y desigualdad. Sobre la "democracia real" a fines del siglo XX. Buenos Aires: CLACSO, 2000. SUBIRATS, Joan. ¿Qué democracia tenemos? ¿Qué democracia queremos?. Perspectivas sobre el Estado, las políticas públicas y la gestión, v. 1, n. 1, p. 10-42, 2013.

TAYLOR, Charles. The politics of recognition. En: HEBLE, Ajay; PENNEE, Donna Palmateer; STRUTHERS, J. R. (eds.). New contexts of Canadian criticisms. Peterborough: Broadview Press, 1997.

TROUILLOT, Michel-Rolph. Ficciones del Atlántico Norte: transformaciones globales, 1492-1945. En:TROUILLOT, Michel-Rolph. Transformaciones globales. La antropología y el 
mundo moderno. Popayán: Universidad del Cauda, 2011.

YASHAR, Deborah. Contesting citizenship in Latin America.

The rise of indigenous movements and the postliberal challenge America. Nueva York: Cambridge University Press, 2005.
WADE, Peter. Población negra y la cuestión identitaria en América Latina. Universitas Humanística, n. 65, p. 117-137, 2008. WILLIAMS, Raymond. Teoría cultural. En: WILLIAMS, Raymond. Marxismo y literatura. Barcelona: Península, 1980.

\title{
Indigenous peoples and democracy in Argentina: advances and challenges
}

\begin{abstract}
:
This paper reflects on progress, obstacles and challenges of the Argentinian state model, democracy and democratization process in relation to visibility-invisibility of indigenous peoples from 1990 to 2014. It inquiries about the continuities/discontinuities between a democratic order of neoliberal character and a national-popular one in relation to indigenous issues. Specifically, the paper exposes some concerns regarding the relationship between the State and indigenous peoples in the period, which can be deepened in future research.To do this, based on the literature about legal devices produced since the enactment of the Comprehensive Indigenous Act in 1985 and the culture studies, the focus lies in the creation in 2009 and the intervention in the public arena of the National Encounter of Territorial Organizations of Indigenous Peoples (ENOTPO). From there, the aim is to advance in (re) thinking issues such as democracy and democratization.
\end{abstract}

Key words: democracy; democratization; State; indigenous people; ENOTPO.

\section{Os povos originários e a democracia na Argentina: avanços e desafios}

\section{Resumo:}

Este trabalho reflete sobre os progressos, obstáculos e desafios do modelo de Estado, da democracia e da democratização argentinas em relação ao processo de visibilidade-invisibilidade dos povos indígenas, entre 1990 e 2014. Questiona sobre as continuidades/descontinuidades entre uma ordem democrática de caráter neoliberal e outra de corte nacional-popular a respeito da questão indígena. Especificamente, busca deixar expostas algumas preocupações a respeito da relação entre o Estado e os povos indígenas no período, que podem ser aprofundadas em futuras pesquisas. Para fazer isso, a partir da literatura sobre os dispositivos legais produzidos desde a promulgação da Lei Integral Indígena em 1985 e dos estudos culturais, o foco do trabalho está na aparição em 2009 e na intervenção no espaço público do Encontro Nacional de Organizações Territoriais de Povos Originários (ENOTPO). A partir daí, se pretende avançar em (re) pensar questões como a democracia e a democratização.

Palavras-chave: democracia; democratização; Estado; povos originários; ENOTPO. 